\title{
The tensile strength test of thermoplastic materials based on poly(butylene terephtalate)
}

\author{
Anna Rzepecka ${ }^{1, *}$, and Monika Ostapiuk ${ }^{1}$ \\ ${ }^{1}$ Lublin University of Technology, Department of Materials Engineering, Nadbystrzycka St. 36, 20-618 Lublin, Poland
}

\begin{abstract}
Thermoplastic composites go toward making an increasingly greater percentage of all manufacturing polymer composites. They have a lot of beneficial properties and their manufacturing using injecting and extrusion methods is a very easy and cheap process. Their properties significantly overtake the properties of traditional materials and it is the reason for their use. Scientists are continuously carrying out research to find new applications of composites materials in new industries, not only in the automotive or aircraft industry. When thermoplastic composites are manufactured a very important factor is the appropriate accommodation of tensile strength to their predestination. Scientists need to know the behaviour of these materials during the impact of different forces, and the factors of working in normal conditions too. The main aim of this article was macroscopic and microscopic analysis of the structure of thermoplastic composites after static tensile strength test. Materials which were analysed were thermoplastic materials which have poly(butylene terephthalate) - PBT matrix reinforced with different content glass fibres - from $10 \%$ for $30 \%$. In addition, research showed the necessary force to receive fracture and set their distinguishing characteristic down.
\end{abstract}

\section{Introduction}

Thermoplastic composites determine a small percentage in all produced polymer composites, because they have only relatively recently been in the market. Scientists observe a steady increase in the interest of these materials, whereas duroplastic composites are no longer used. When we compare both types of materials we predict that the first type of materials will displace duroplastic composites because they have better properties. Manufacturing thermoplastic composites using injecting and extrusion methods are easier and cheaper methods than manufacturing duroplastic composites. Other benefits are easier recycling, bigger impact strength, improved fracture toughness, easier moulding material and low density, so low mass too - all these properties mean they are used in different industries, for example the automotive or aircraft industry [1].

Because they are used in very responsible parts in machines, and in different elements, a very important aspect is tensile strength. Thermoplastic composites can be destroyed in two ways. Fibres, which are used to reinforce materials, can be broken so different fibres can be overloaded and this situation leads to broken composites. The second way is the stretching of certain fibres that have small adhesion to matrix. The reason for this can be defects in boundary fibre/matrix or mistakes during manufacturing of materials [2].

So during planning and manufacturing methods of thermoplastic composites it is very important is consort with a lot of factors and aspects to create materials with the best properties. Not only the kind of force, but also the structure of boundary layers too and the defects that exist there can influence stability and quality of the connection fibre/matrix. Composites during exploration are exposed to different types of outside strains which can be begin to form micro-cracks which develop from existing defects [3]. This behaviour can lead to previous broken composite elements so to generate a good connection is one of the biggest problems during examination composite materials.

Banik K. [4] the effect of mould temperature variation on the short and long-term behaviour of injection melded PBT were presented. The results indicated that the influence of mould temperature variation has little manifestation from the tensile and impact properties of the moulded PBT parts, but while considering their creep and dynamic mechanical behaviour, they show a significant effect. This deformation behaviour could be explained by the influence of processing conditions on the semi-crystalline morphology, particularly crystallinity as well as molecular packing density of the moulded PBT parts [4]. Regarding the lack of knowledge in terms of the precise understanding on the failure basis on the interface between fibre and thermoplastic, there have not been many publications on the degradation mechanisms especially after tensile strength of PBT with short glass fibres.

So in this paper, a PBT/short fibre fillers composite has been introduced trying to show and discuss the

\footnotetext{
Corresponding author: annarzepecka92@gmail.com
} 
phenomena and structure characterization after tensile strength test.

\section{Materials and methods}

The chosen polymer was glass fibre reinforced PBT (poly(butylene terephthalate)) - Celanex ${ }^{\circledR}$ (Celanese, USA) containing $10 \%, 20 \%$ and $30 \%$ glass fibres. Corresponding material symbols i.e. PBT10\% for PBT $20 \%$ and $\mathrm{PBT} 30 \%$ in order to simplify the notation. Injection moulding processing conditions as suggested in Processing Guide for Celanex ${ }^{\circledR}$ (product of Celanese Corporation) were presented in Table 1. It was taken for tests 5 samples from one kind of materials. However, the graph was only showing for 3 samples.

Table 1. Parameters of injection process for materials CELANEX 10, 20,30\%.

\begin{tabular}{|c|c|}
\hline Parameters & Value \\
\hline Melting point $\left[{ }^{\circ} \mathrm{C}\right]$ & $260-270$ \\
\hline Temperature of cast $\left[{ }^{\circ} \mathrm{C}\right]$ & $75-85$ \\
\hline Speed of inject & fast \\
\hline Returnable pressure $[\mathrm{bar}]$ & $10-30$ \\
\hline Inject pressure $[\mathrm{bar}]$ & $600-1000$ \\
\hline Holding pressure $[\mathrm{bar}]$ & $400-800$ \\
\hline
\end{tabular}

Macro-structural analysis was carried out on stereoscopic microscope (Nikon SMZ100, Japan). Micro-structural analysis was performed with using an optical microscope (Nikon MA200, Japan) and scanning electron microscope (NovaNano SEM450, FEI). Metallographic micro-sections have been prepared in accordance with the methodology of the author and with methodology created by Buehler Company using materials supplied by Buehler and Struers. Testing samples were not subjected to etching.

Tensile strength test were used with the specifications of PN EN ISO 527-2 and were carried out on ZWICK100 testing machine. These tests were undertaken at a crosshead displacement of $5 \mathrm{~mm} / \mathrm{min}$.

\section{Results}

\subsection{Tensile strength test}

In Figure $1(a, b, c)$ are charts for three select samples and their dependence of force from displacement for PBT samples $10 \%, 20 \%$ and $30 \%$. The sample is the lowest for PBT $10 \%$ whereas the biggest for PBT is $30 \%$ and run value about $6000 \mathrm{~N}$. Experiments were conducted to complete destruction samples what is the end of curve on the Figures.
Table 2 shows selected parameters of tensile strength samples PBT 10, 20,30\%. It shows what the lowest force to broken sample is for material with $10 \%$ glass fibres and the biggest for $30 \%$ glass fibres. The difference in force needed to break the samples between these two types of material was about 2000 N. PBT $20 \%$ shows intermediate value. Similarly as in case of value of yield strength and Young's modulus.

a)

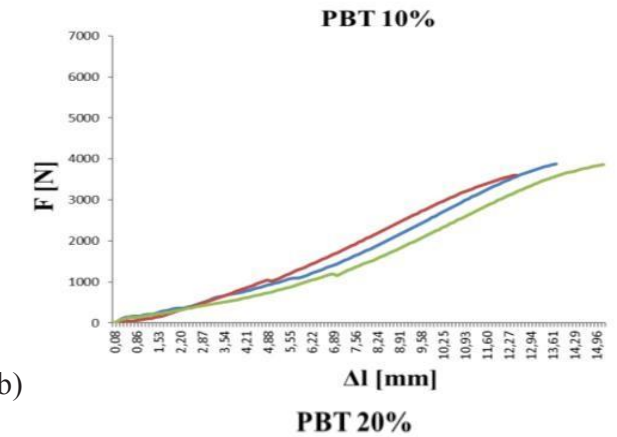

c)
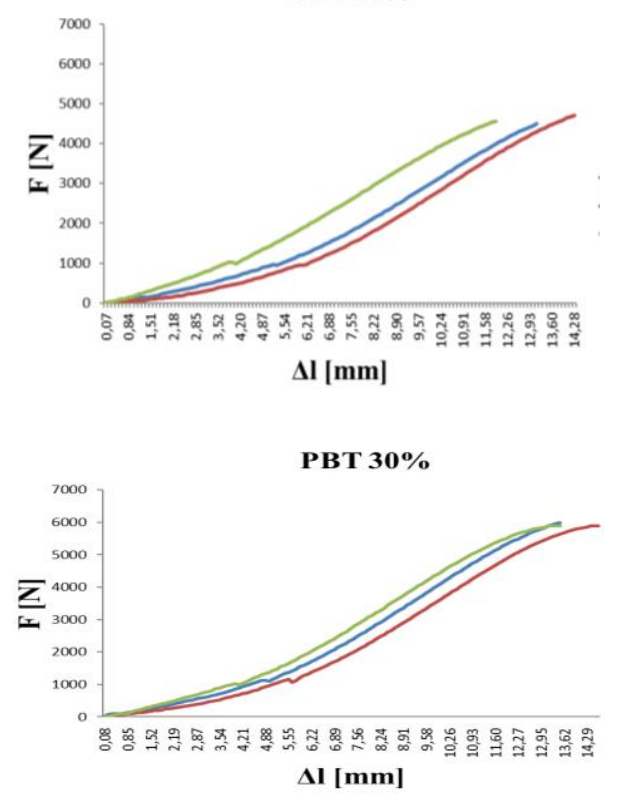

Fig. 1. Dependence of force F from displacement $\Delta \mathrm{l}$ for a) $10 \%$ glass fibres b) $20 \%$ glass fibres c) $30 \%$ glass fibres.

Table 2. Select parameters of tensile strength for sample PBT.

\begin{tabular}{|c|c|c|c|}
\hline $\begin{array}{l}\text { Kind of } \\
\text { material }\end{array}$ & $\mathrm{F}[\mathrm{N}\}$ & $\mathrm{Rm}[\mathrm{MPa}]$ & $\begin{array}{c}\text { Young's } \\
\text { Modulus } \\
{[\mathrm{GPA}]}\end{array}$ \\
\hline PBT10\% & $3820 \pm 250$ & $92 \pm 3,21$ & $4,87 \pm 0,75$ \\
\hline PBT 20\% & $4560 \pm 176$ & $120 \pm 5$ & $6,95 \pm 1,04$ \\
\hline PBT 30\% & $5900 \pm 40$ & $147 \pm 6$ & $9,76 \pm 1,45$ \\
\hline
\end{tabular}

\subsection{Macroscopic observation}

In Figure 2 are examples of microscopy images samples after being broken. It shows that for sample PBT $10 \%$ breakthrough is the least fragile character whereas for 
samples $20 \%$ and $30 \%$ fragile breakthroughs are more visible. All samples were broken in middle part of paddles.

a)

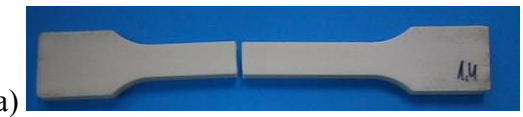

b)

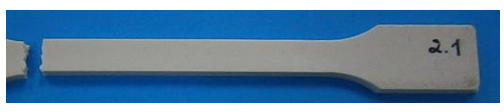

c)

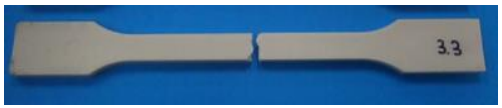

Fig. 2. Breakthroughs of samples after tensile test a) $10 \%$ glass fibres b) $20 \%$ glass fibres c) $30 \%$ glass fibres.

a)

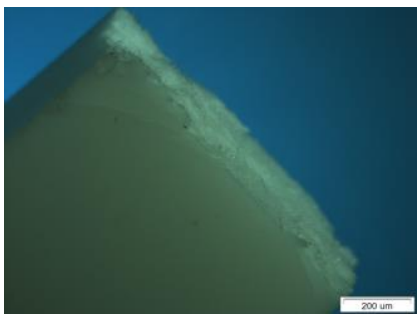

b)

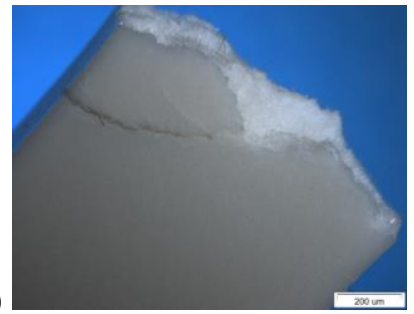

c)

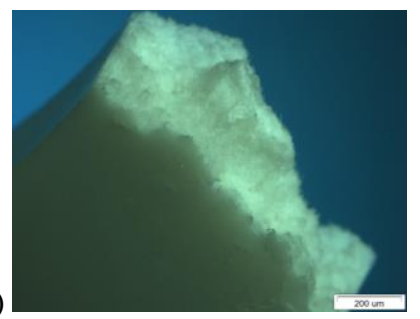

Fig. 3. Breakthroughs of samples a) $10 \%$ glass fibres b) $20 \%$ glass fibres c) $30 \%$ glass fibres; stereoscopic microscope.

Using scanning microscopy, we get the character of breakthroughs. We can see that the fragile character of samples shows interim breakthroughs. Furthermore, we can see individual fibres project from breakthroughs. For samples PBT $10 \%$ we cannot see destruct matrix but in the case of PBT $20 \%$ and $30 \%$ it is present, which is shown in Figure $3(a, b, c)$.

\subsection{Microstructural observation}

Figures $4,5 \& 6$ shows panoramic photos with photos developed from the assembly sequence. In Figure 4 we can singularise inner part and core that is typical for injection methods. In inner part is different composition of fibres than in core. Composition of fibre is chaotic enough. The dominate type of composition is composition at an angle bigger than $0^{\circ}$ on inboard profile in the core but inner part direction aim at to $0^{\circ}$. On microstructure photos, we can see different content of fibres for every type of sample.

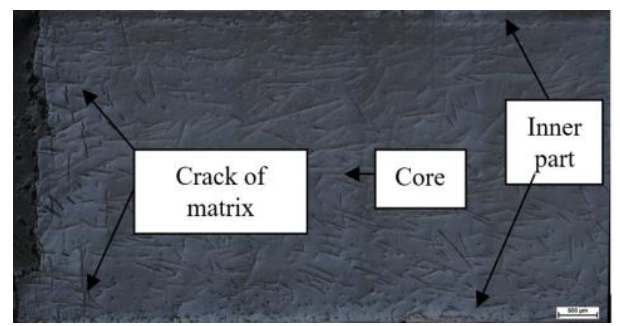

Fig. 4. Panoramic view of microstructure for PBT $10 \%$; optical microscope.

Panoramic photo from Figure 5 shows the inner part and core too. In the case of sample PBT 20\% a larger amount of glass fibres is visible. The composition of fibre is still chaotic but there exists a bigger aggregation. In microstructure, we cannot see individual cracks in matrix like in case of PBT $10 \%$. We can see visual degradation of matrix in the inner part of the sample and it means lower tensile strength fibres in this composition.

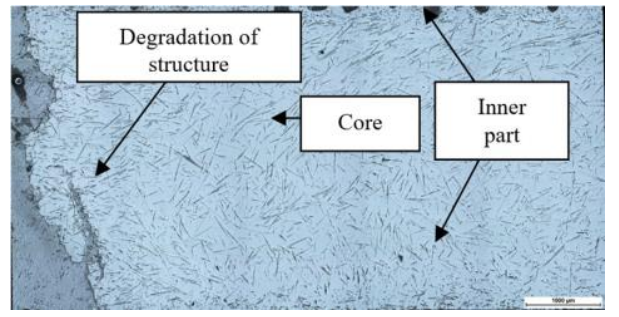

Fig. 5. Panoramic of microstructure for PBT 20\%; optical microscope.

In Figure 6 we can see the biggest aggregation of fibres and this means the biggest contest of glass fibres in sample (PBT 30\%). The biggest degradation of sample exists in the core. In this case, the inner part has the biggest tensile strength. The reason for this situation is the different direction of composition fibres. Fibres that exist in the core mark significant elongating. On microstructure 7,8 we can distinguish small cracks on board of fibres, cracks of resin and cracks between fibres.

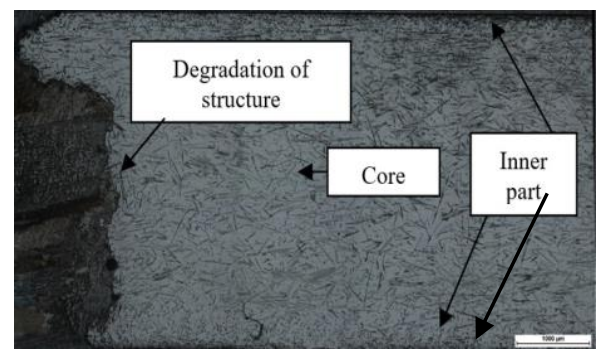

Fig. 6. Panoramic of microstructure for PBT 30; optical microscope.

Figure $9(\mathrm{a}, \mathrm{b})$ shows microstructures in which the characteristic are a large amount of cracks not only on board of the breakthrough but also deep into the core. These cracks exist in opposite directions than operate tensile force. 
After detailed microstructural analysis we can see not only cracks of the matrix but also cracks of fibres, cracks on board the matrix/fibre, debonding with separation between the matrix and fibre $[5,6]$.
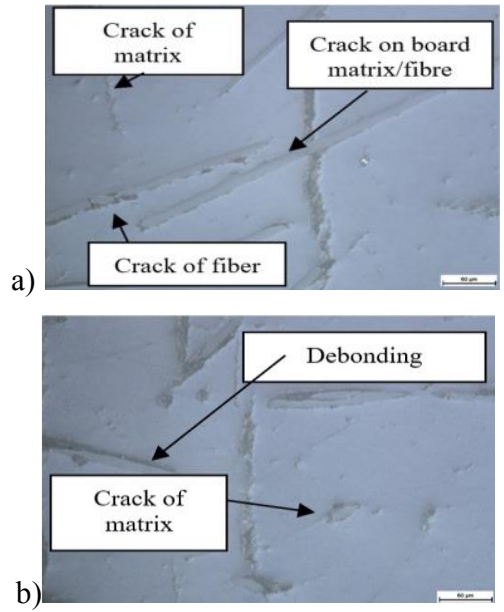

Fig. 7. Microstructure of PBT 10\% a) different type of cracks b) debonding; optical microscope.

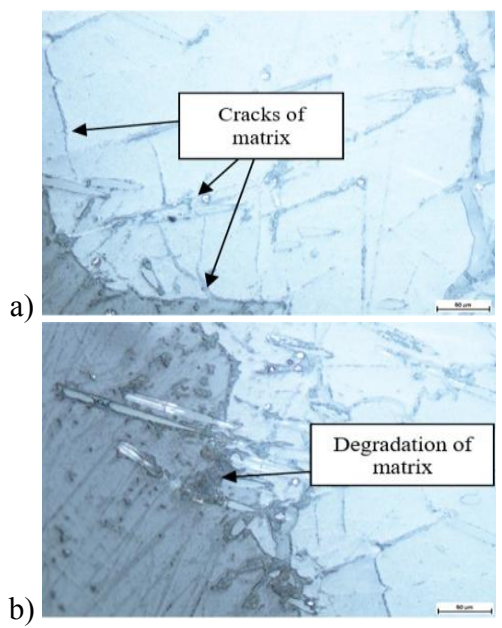

Fig. 8. Microstructure of PBT 20\% a) different type of cracks b) debonding; optical microscope.
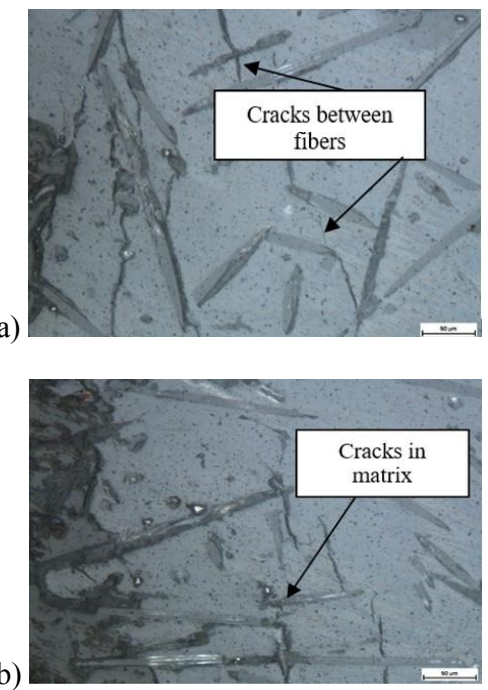

Fig. 9. Microstructure of PBT 30\% a) different type of cracks b) debonding; optical microscope.
Figure $10(\mathrm{a}, \mathrm{b}, \mathrm{c})$ shows images of breakthrough using scanning microscope.
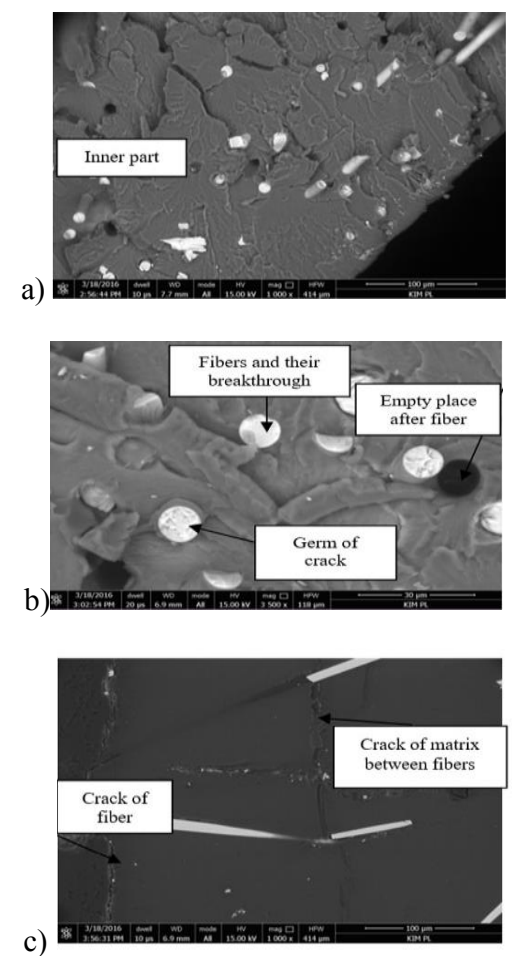

Fig. 10. PBT 10\% a),b) breakthroughs c) microstructure; SEM.

In the case of Figure 10, composition indicates inner part of sample. After analysis, we can gather that fibres were broken or were hoick out of place from where they were. Breakthrough shows that here exists the appearance of shortcrust crack. We can see cracks line from fibre too. The reason of this is because of the fact that fibre have a larger strength than matix. One of the basic qualities of polymer composites is the characteristic surface of matrix (textured microflow). We can see cracks of fibres and cracks between fibres $[7,8]$.

Figure 11 shows core of samples. Concentration of fibres testifies to the larger amount of glass fibres in structure. On breakthroughs, the amount placed after draw out of fibres is greater too. In this case, matrix is kept in a different way than sample PBT $10 \%$. There are fewer lines shown in the texture of matrix. The appearance does not exist in PBT 10\% but what exists here is fibre imprints with trails after fibres in matrix. Fibers that stick out from the matrix aren't the last of the matrix and is possible when we are using different types of fibres. On microstructure we can see cracks of matrix and cracks of fibres $[7,9,10]$.

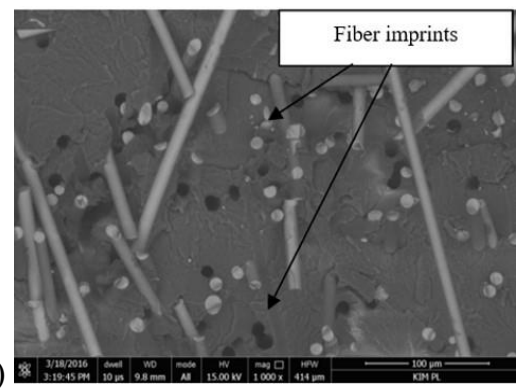


b)

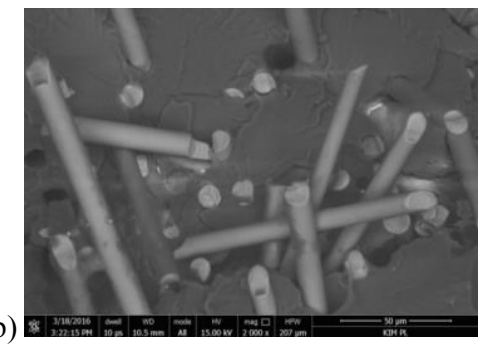

c)

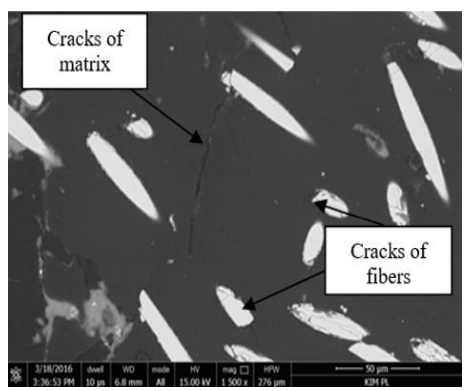

Fig. 11. PBT 20\% a), b) breakthroughs c) microstructure; SEM.

Degradation of sample PBT $30 \%$ is different than samples with $10 \%$ and $20 \%$ glass fibres. The reason for this fact is that in PBT 30\% we have a greater amount of fibres in the structure. The new appearance is the apparition of debris with the last of matrix. In Figures 11 and 12 , we can see cracks of matrix and cracks of fibres too. Whereas on microstructure cracks on matrix and destroyed fibres [7,11].

Hull [12] argued that a further factor which influences the fracture is the fibre/ matrix interfacial strength. This parameter dictates whether matrix/fibre debonding or fibre fracture controls the failure processes and material toughness.

Hahn [13] said that the reinforcement architecture significantly affects the manner in which the side composite breaks. This variation of orientation within the material can lead to localized weakening, highly anisotropic regions, which are often associated with failure orientation in components [14].

a)

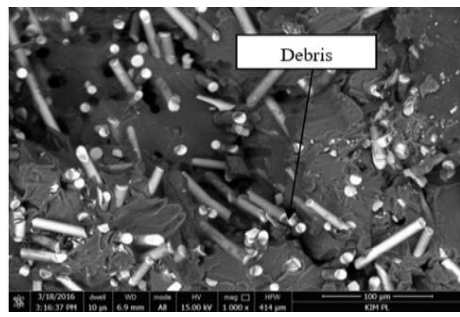

b)

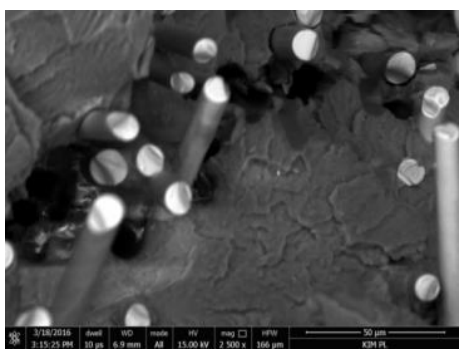

c)

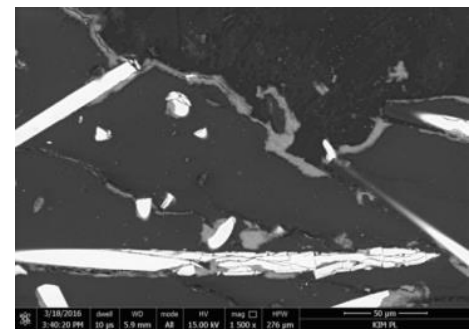

Fig. 12. PBT $30 \%$ a),b) breakthroughs c) microstructure; SEM.

Wang [15] concluded that a key parameter that is often the contributing factor to the failure of short fibre composites is the local fibre volume fraction. In regions where the fibre volume fraction is low, the material is locally weaker and brittle. Consequently, matrix features can be used to interpret the fracture directions at these sites [14].

In short fibre composites cracks often initiate from voids or micro-cracks at the fibre and propagate in the matrix until they are arrested by neighbouring fibres. Failure can then propagate through a number of mechanisms such as fibre/ matrix debonding, in-plane delamination, fibre fracture and fibre pullout [14].

\section{Conclusion}

Polymer composites are used, with good grace, in many types of industry. It is the reason to do research in order to get to know the attitude of this material and the influence on different forces and factors and to imitate an environment of work. There still exists work to make composite materials better and better, for example to make new combinations of fibre/matrix and examine their properties. One of these examples is the examination of tensile strength. In this article we show, agreeably with the main aim, results after statistic tensile strength and structural analysis of polymer composites poly(butylene terephthalate) with different content of glass fibres $-10,20$ and $30 \%$.

Degradation of samples were the biggest in the core part and it means that composition of fibres in the inner part have the largest tensile strength. In materials, there are many defects: cracks of fibres, cracks on board matrix/fibre, cracks between fibres and debonding. On breakthrough, we can see the growth of cracks and lines from this place so it means that breakthrough has a brittle character. This way of breaking is very dangerous due to flow being very fast after the advanced designated value of strains. The structure of the matrix shows its characteristics in places, in which we can see fibre imprints and debris.

I would like to say thank you to Mr. Adam Bartoszek for his cooperation and sharing the samples to perform this research (Account Development Manager Poland, Celanese Engineering Materials).

The present study was supported by grants S2/MN/2017 from the Faculty of Mechanical Engineering. 


\section{References}

1. J. M. Hodgkinson, Woodhead Publishing Limited (2000)

2. L. St-Pierre, N.J. Martorell, S.T. Pinho, Composite Structures 168 (2017)

3. D. D. L. Chung, Materials Science and Engineering : R : Reports 113 (2017)

4. K. Banik, G. Mennig, Mech-time Dependent Mater 9 (2006)

5. J.Liu, G. Zhang, Composites Science and Technology 98 (2014)

6. U. Chaduvula B.V.S. Viswanadham, J. Kodikara, Applied Clay Science 142 (2017)

7. E. S. Greenhalgh, Woodhead Publishing Limited (2009)
8. S. Mortazavian, A. Fatemi, Composites: Part B 72 (2015)

9. B. Klimkeit, S. Castagnet, Y. Nadot, A. El Habib, G. Benoit, S. Bergamo, C. Dumas, S. Achard, Materials Science and Engineering A 528 (2011)

10. B. Madsen, Mustafa Aslan, Hans Lilholt, Composites Science and Technology 123 (2016)

11. Z. Jiang, L. A. Gyurova and others, Composites Science and Technology 68 (2008)

12. D. Hull, Cambridge University Press (1999)

13. H. Hahn, K. Jerina, F. Burrett, ASTM Special Technical Publication 183 (1989)

14. M. Ostapiuk, Materials Engineering 5 (2016)

15. L. Wang L., W. C. Tjiu, S.F. Teh, C.B. He, T.X. Liu, Polymer Composites 26 (2005) 